\title{
The authors reply
}

\section{Francesco Bertolini, Yuval Shaked, Patrizia Mancuso and Robert S. Kerbel}

The Division of Hematology-Oncology, Department of Medicine, European Instituteof Oncology, 20141

Milan, Italy.

The Sunnybrook Health Sciences Centre, Molecular and Cellular Biology, Department of Medical Biophysics, University of Toronto, Toronto, Ontario M4N 3M5, Canada.

Correspondence to F.B. e-mail: francesco.bertolini@ieo.it

We thank Gagner and Shamamian for their interesting comments. For the sake of brevity, we had not discussed in detail in our review the issue of CD45 expression in CEPs. In most clinical studies published so far in cancer or cardiovascular medicine, CEPs have been counted by flow cytometry according to the expression of CD133 or CD34, and data about CD45 expression were not available. Similarly, in many preclinical studies in mice (in which CD133 expression is usually not investigated), CD45 expression data are lacking. In our experience, the large majority of human $\mathrm{CD} 133^{+}$and $\mathrm{CD} 34^{+}$cells also express $\mathrm{CD} 45$, a phenotype compatible with haematopietic stem and/or progenitor cells. A tiny subpopulation (usually $<10 \%$ ) of human $\mathrm{CD}_{133^{+}}$or $\mathrm{CD} 34^{+}$cells lack CD45 expression or is CD45 ${ }^{\mathrm{dim}}$, therefore suggesting that these cells might not be fully committed to the haematopoietic lineage. However, after purification by cell sorting, either $\mathrm{CD} 133^{+} \mathrm{CD} 45^{-}$and $\mathrm{CD} 133^{+} \mathrm{CD} 45^{+}$cells were able to generate human mature endothelial cells in immunodeficient mice (albeit at different frequencies), therefore suggesting that CD45 expression does not definitively hamper the endothelial potential of a progenitor (P.M. and F.B., unpublished observations). Regarding the clinical predictive potential of CEPs defined as $\mathrm{CD} 45^{+}$or $\mathrm{CD} 45^{-}$or $\mathrm{CD} 45^{\mathrm{dim}}$, in our recent clinical studies in patients with breast cancer who received metronomic chemotherapy ${ }^{1}$ we found that the total number of $\mathrm{CD} 133^{+}$progenitor cells (independently from CD45 expression, studied in detail by different gating strategies) did not correlate with the clinical outcome. We fully agree with Gagner and Shamamian that these inconclusive results probably reflect our limited understanding of CEP origin and differentiation steps in adults, and that more research is warranted in this area.

1. Mancuso, P. et al. Circulating endothelial cell kinetics and viability predict survival in breast cancer patients receiving metronomic chemotherapy. Blood 108, 452-459 (2006). 